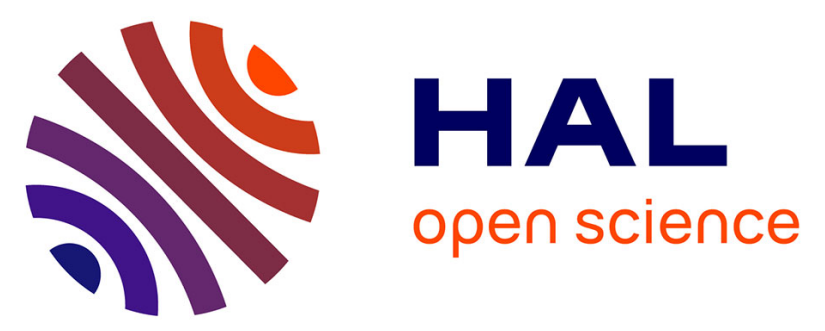

\title{
Modelling and control of a travelling wave in a finite beam, using multi-modal approach and vector control method
}

Sofiane Ghenna, Frédéric Giraud, Christophe Giraud-Audine, Michel Amberg, Betty Lemaire-Semail

\section{To cite this version:}

Sofiane Ghenna, Frédéric Giraud, Christophe Giraud-Audine, Michel Amberg, Betty Lemaire-Semail. Modelling and control of a travelling wave in a finite beam, using multi-modal approach and vector control method. IEEE International Frequency Control Symposium \& European Frequency and Time Forum will, Apr 2015, Denver, Colorado, USA, United States. 10.1109/FCS.2015.7138895 . hal01201877

\section{HAL Id: hal-01201877 \\ https://inria.hal.science/hal-01201877}

Submitted on 18 Sep 2015

HAL is a multi-disciplinary open access archive for the deposit and dissemination of scientific research documents, whether they are published or not. The documents may come from teaching and research institutions in France or abroad, or from public or private research centers.
L'archive ouverte pluridisciplinaire HAL, est destinée au dépôt et à la diffusion de documents scientifiques de niveau recherche, publiés ou non, émanant des établissements d'enseignement et de recherche français ou étrangers, des laboratoires publics ou privés. 


\title{
Modelling and control of a travelling wave in a finite beam, using multi-modal approach and vector control method
}

\author{
Sofiane GHENNA ${ }^{1,2}$, Frédéric GIRAUD ${ }^{1,2}$, Christophe GIRAUD-AUDINE ${ }^{1,3}$, \\ Michel AMBERG ${ }^{1,2}$, and Betty LEMAIRE-SEMAIL ${ }^{1,2}$ \\ ${ }^{1}$ Laboratoire d'Electrotechnique et d'Electronique de Puissance \\ IRCICA, 50 avenue Halley, 59650 Villeneuve d'Ascq, France \\ ${ }^{2}$ Université Lille1, 59650 Villeneuve d'Ascq, France \\ ${ }^{3}$ Arts et Métiers Paris-Tech \\ Centre de Lille, 8 bd Louis XIV, 59046 Lille
}

\begin{abstract}
This paper presents a new method to produce and control the vibration amplitude and direction of a travelling wave in a finite beam, using multi-modal approach. A closed loop control of the transducer vibration is applied using vector control method. the modelling in rotating frame and the decoupling according to two-axis allows to obtain a double independent closed loop control. This allows to regulate the vibration amplitude of the travelling wave directly. An analytical modelling is presented, with experimental validation, showing good performances even in the presence of perturbations.
\end{abstract}

Keywords: Traveling wave, Linear motor, Langevin transducer, Multimodal approach, Vector control

\section{INTRODUCTION}

Several studies are focused on the generation of travelling waves on a beam, to realize linear motor for instance. In [1], a travelling wave using two transducers is presented in an early work by Sashida. One transducer is used to produce the travelling wave, while the other absorbs it to prevent the formation of standing wave. It should be noted that this method requires impedance matching, between the beam and a transducer as described in [2]. The second method [3]-[7] is based on the excitation of two successive flexion modes of the beam, which are excited by forces produced by two transducers. These forces are shifted by $90^{\circ}$ and generated at the center frequency between the two modes. The advantage is that the impedance matching is no more required and so changing direction can be achieved by changing the phase difference from $90^{\circ}$ to $-90^{\circ}$. However, these methods are in open loop control and cannot control the vibration amplitude in the presence of disturbance. In [8], the authors proposed a closed-loop control of transducers to produce a travelling wave using the second method, even changing frequency, the travelling wave can be obtained by this control. However the vibration amplitude is low because of the used piezoelectric actuator, this travelling wave is controlled in direction but not in amplitude.

In this work, this latest approach is improved by controlling the vibration of each transducer in a rotating frame. It is then possible to control the amplitude of each actuator and their relative phase shift. This allows the control of both direction and vibration amplitude of the produced travelling wave, and the effect of the beam is rejected as a perturbation. Hence, it is necessary to model only the transducers. Experiments have shown that it was possible to control phase and amplitude even in transient and obtained a large travelling wave with standing wave ratio nearly equal to one. The principal applications domain of travelling wave are acoustic levitation [9]-[11], piezoelectric miniature robot [12], [13], Transportation of objects using linear ultrasonic motor [14]-[18].

In the first part, the principle of a new excitation method of vibration modes, using multi-modal approach is presented, with analytical modelling, showing the possibility to excite the beam with vibration amplitude. In the second part, the design of the beam and horns are addressed, then the control method is proposed, allowing to control the travelling wave in both direction and vibration amplitude, using vector control method. Finally experimental results are provided in the last part.

\section{MULTI-MODAL APPROACH}

\section{A. Forced vibration in finite beam}

We consider a thin beam, with rectangular cross section denoted by $A$, length by $L . \rho, E$ are respectively density and modulus of elasticity, $I$ is the quadratic momentum of the beam. The transverse vibration of a uniform elastic homogeneous isotropic Euler-Bernoulli beam [19] can be written in Cartesian coordinates as

$$
E I \frac{\delta^{4} w}{x^{4}}+\rho A \frac{\delta^{2} w}{\delta t^{2}}+r_{a} \frac{\delta w}{\delta t}=p(x, t)
$$

with: $w(x, y, z, t)=w(x, t)$ the deflection of the beam at point $x$ and time $t$, and $p(x, t)$ denotes the load per unit length of the beam at point $x$ and time $t$, while $r_{a}$ represents the coefficient of external damping of the beam.

It is possible to determine the deformation mode shapes, and the frequency spectrum of the beam, by using the analytical 
model of Euler-Bernoulli eq.1 developed in [20]. In this paper, harmonic vibrations are only considered enabling the use of the complex notation so that: $\underline{w}$, with $w$ is the real part of $\underline{w}$. If we take into account the contribution of every vibration mode excited in the beam, then the vibration can be written by:

$$
\underline{w}(x, t)=\sum_{n=1}^{\infty} \underline{W_{n}} \phi_{n}(x) e^{j \omega t}
$$

Where $\underline{w}$ includes real and imaginary part of the vibration, at location $x$, and time $t, \omega$ is the angular frequency of the flexural wave, and $j=\sqrt{-1}$.

$\phi_{n}(x)$ is the deformation mode shapes of the $n^{\text {th }}$ mode, and is fixed for the beam.

$\underline{W_{n}}$ represents the modal amplitude of the $n^{\text {th }}$ mode. We suppose that we can control each mode independently. Hence, the deformation $\underline{w}(x, t)$ depends theoretically on an infinite degrees of freedom which are $W_{n}$. This property is used to generate and to control the travelling wave detailed here after. we restrict the study to two vibration modes denoted A and B. In this paper, only harmonic vibrations are considered enabling the use of the complex notation with $\underline{x}=\underline{X} e^{j \omega t}$, where $\underline{X}=X e^{j \alpha}, \alpha$ and $X$ are respectively the argument and the magnitude of $\underline{X}$ so much that:

$$
\underline{W}(x)=\underline{W}_{A} \phi_{A}(x)+\underline{W}_{B} \phi_{B}(x)
$$

From the superposition of two flexion modes, it is possible to obtain a function $\underline{W}(x)$ which depends on the modal amplitude $\underline{W}_{A}$ and $\underline{W}_{B}$. To obtain this, we need a specific excitation conditions of vibration modes $\underline{W}_{n}$, a multi-modal approach thus is required to realize this.

\section{B. Two modes excitation}

The multi-modal approach consists in exciting two successive flexion modes of the beam. The frequency is chosen in the vicinity of the center frequency of their resonant frequency, as depicted in Fig.1. In this work the frequency does not have to be chosen right in the middle. The dimensions of the

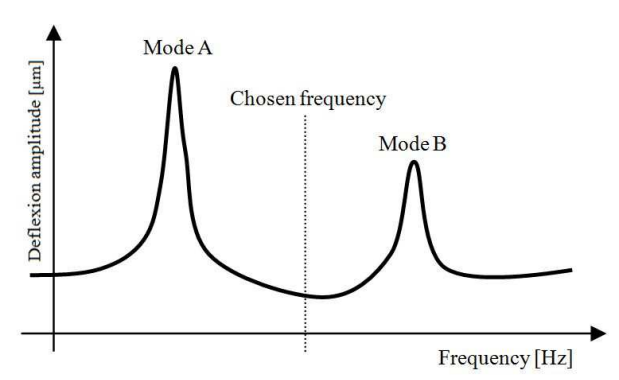

Fig. 1. Excitation between two successive flexion modes

beam are adjusted in order to have the modes $\mathrm{A}$ and $\mathrm{B}$ placed apart of the transducers resonance frequency which is $28 \mathrm{kHz}$. Figure 2 shows a beam operated by two piezoelectric actuators located at distance $x_{1}, x_{2}$ from each end of the beam, (the

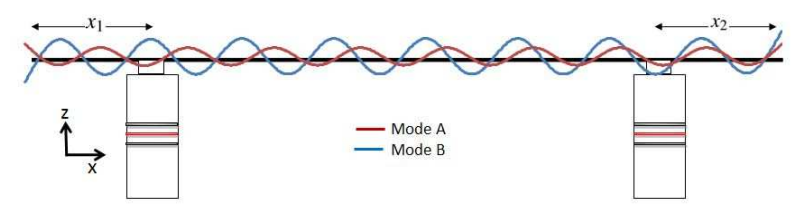

Fig. 2. Generating principle of two successive flexion modes

red and blue curve represent vibration mode $\mathrm{A}$, and mode $\mathrm{B}$ respectively). A travelling wave is obtained if $W_{A}$ is shifted by $90^{\circ}$ compared to $W_{B}$ with a same amplitude accordingly to [6], the vibration amplitude on the beam $\underline{W}\left(x_{i}\right)$, depends on both of the deformation mode shapes, and their modal amplitude. If we consider two given points of the beam $x_{1}$ and $x_{2}$ (position of the actuators), the harmonic vibration at these positions is given by:

$$
\begin{aligned}
& \underline{W}\left(x_{1}\right)=\underline{W}_{A} \phi_{A}\left(x_{1}\right)+\underline{W}_{B} \phi_{B}\left(x_{1}\right) \\
& \underline{W}\left(x_{2}\right)=\underline{W}_{A} \phi_{A}\left(x_{2}\right)+\underline{W}_{B} \phi_{B}\left(x_{2}\right)
\end{aligned}
$$

where $\underline{W}\left(x_{1}\right)$ and $\underline{W}\left(x_{2}\right)$ are the vibration amplitude of the first and the second actuator, denoted respectively by $W_{1}, W_{2}$. Introducing the matrix notation, eq. 4 and eq. 5 become:

$$
\left(\begin{array}{l}
\underline{W}_{1} \\
\underline{W}_{2}
\end{array}\right)=\left(\begin{array}{ll}
\phi_{A}\left(x_{1}\right) & \phi_{B}\left(x_{1}\right) \\
\phi_{A}\left(x_{2}\right) & \phi_{B}\left(x_{2}\right)
\end{array}\right)\left(\begin{array}{l}
\underline{W}_{A} \\
\underline{W}_{B}
\end{array}\right)
$$

giving rise to :

$$
\left(\frac{\underline{W}_{1}}{\underline{W}_{2}}\right)=\phi_{x_{1}, x_{2}}\left(\underline{\underline{W}}_{B}\right)
$$

Inversely if the position of transducers does not represent nodes

$$
\left(\underline{W}_{A}\right)=\phi_{x_{1}, x_{2}}^{-1}\left(\underline{\underline{W}}_{B}\right)
$$

The vibrations of transducers impose the dynamic of the modal amplitudes. Then $\underline{W}_{A}$ and $\underline{W}_{B}$ can be controlled directly by the vibration amplitude of the transducers. In this paper this principle is used to produce control a travelling wave, using excitation with vibration amplitude.

\section{Condition for travelling wave}

It has been shown in [3] that at fixed frequency a travelling wave can be obtained with the same modal amplitudes $\left(W_{A}=\right.$ $W_{B}$ ) shifted by $90^{\circ}$. In rotating frame this is modelled by :

$$
\begin{aligned}
& \underline{W_{A}}=W_{A} e^{j \psi_{A}} \\
& \underline{W_{B}}=W_{A} e^{j \psi_{B}}
\end{aligned}
$$

with:

$$
\psi=\psi_{A}-\psi_{B}= \pm \frac{\pi}{2}
$$

then the necessary condition is

$$
\underline{W_{A}}= \pm j \underline{W_{B}}
$$


Where $W_{A}$ and $W_{B}$ are rotating in the fixed frame, and fixed in the $(d, q)$ frame as described in Fig.3(a). To achieve this, these modal amplitudes must be controlled in order to generate a travelling wave.

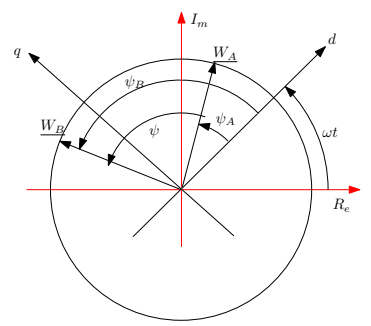

(a) modal amplitudes

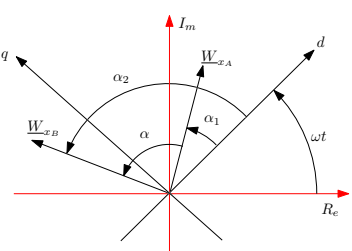

(b) Vibration amplitude
Fig. 3. Argument and magnitude in rotating frame

\section{EXPERIMENT VALIDATION}

\section{A. Design of the beam}

The analytical model of Euler-Bernoulli eq. 1 was simulated to determine the frequency spectrum of the beam given in Fig.5, the deformed mode shapes presented in Fig 5. A beam made of aluminium was chosen, because of the excellent acoustical characteristics of this material, which parameters are given in Tab.I. The dimensions of the beam has been chosen in such a way that the resonance frequency of transducers $28 \mathrm{kHz}$ is in the range between the two resonance modes.

TABLE I

BEAM'S CHARACTERISTIC

\begin{tabular}{|c|c|}
\hline Young's modulus E & $57 \mathrm{GPa}$ \\
\hline Poisson's ratio $\gamma$ & 0.33 \\
\hline Density $\rho$ & $2561 \mathrm{~kg} / \mathrm{m}^{3}$ \\
\hline Length $\mathrm{L}$ & $350 \mathrm{~mm}$ \\
\hline height $\mathrm{h}$ & $6 \mathrm{~mm}$ \\
\hline width $\mathrm{b}$ & $6 \mathrm{~mm}$ \\
\hline
\end{tabular}

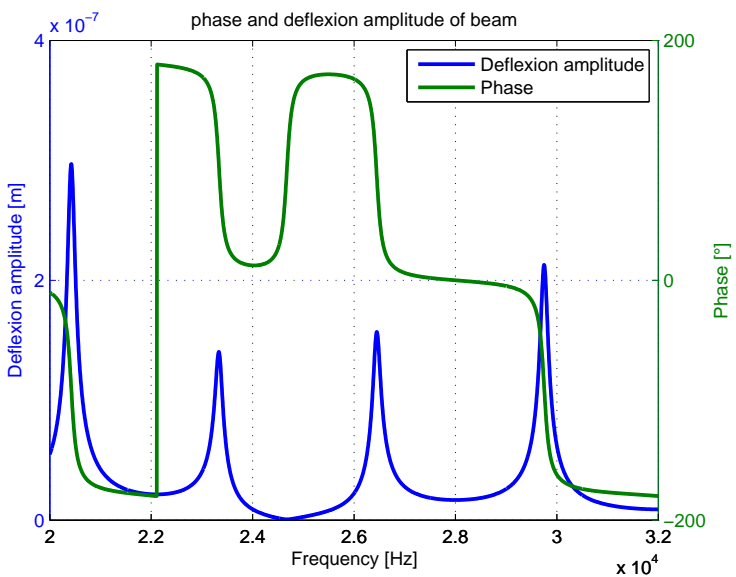

Fig. 4. Frequency spectrum at a given position of the beam
From Fig.4, the choice of the vibration modes was laid on the $16^{\text {th }}$ and $17^{\text {th }}$ mode shape corresponding to $26460 \mathrm{~Hz}$ and $29760 \mathrm{~Hz}$ which are denoted by mode shape A, and B respectively. It should be noted that there are other vibration modes between two successive flexion modes, as extensional and torsional mode, but only bending mode are excited transversely.

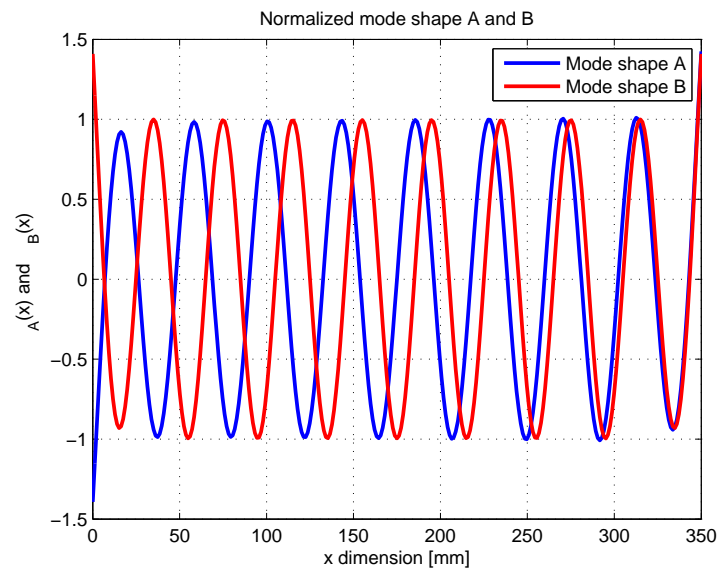

Fig. 5. Simulated normalized mode shape A and B

\section{B. design of the horns}

In order to design the horns, the contact nature between the actuator and the beam must be ensure:

- Punctual Contact: for not to change the boundary conditions (free-free)

- Contact ensuring the stability of the beam: to prevent cause side movements (rotation, translation ...).

- Continuous and reversible contact for transmitting the vibrations. In this case: a screwed contact on a smallest possible diameter of the cone, to limit the surface of contact as shown in Fig.6. The horn is designed with $\lambda / 2$ wavelength, to avoid the interaction forces between the different parts of the transducer. The design of the horns can be found in [22].

\section{Position of transducers}

The two piezoelectric actuators are positioned near the antinodes of each mode, in order to optimizing the electromechanical couplings and to obtain a purely transverse displacement for a non a non zero matrix $\phi_{x_{1}, x_{2}}$. The modal analysis of Fig.5 can be used to determine the position of the transducers on the anti-nodes, or the formula described in [21] can be used.

$$
x_{1}=x_{2}=n \frac{\lambda}{2}+\frac{7}{8}
$$

where $x_{1}, x_{2}$ are the position of the transducers from both ends of the beam, $n$ is an integer, $\lambda$ is the wavelength. The two transducers are placed at $x_{1}=x_{2}=60 \mathrm{~mm}$, at the ends of the beam, with wavelength of $41.5 \mathrm{~mm}$. 


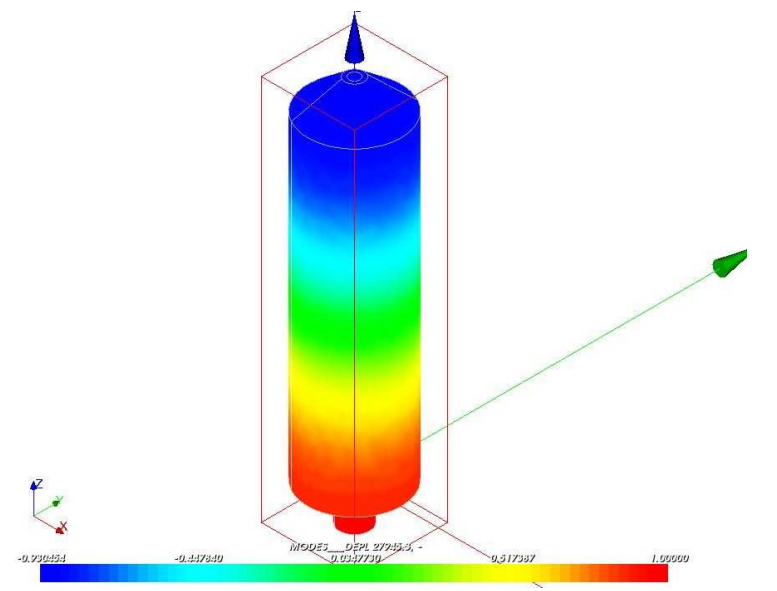

Fig. 6. Design of the horn and simulation of the vibration mode at $28 \mathrm{kHz}$

\section{Experimental test bench}

An aluminium beam is actuated by two Langevin transducers, which were associated with horns. The whole system is fixed on a solid support, which allows to move the beam for measuring the vibration velocity at every point of the beam, using an interferometer (OFV-525/-5000-S) as shown in Fig.7. A graphical user interface is used to control the vibrations

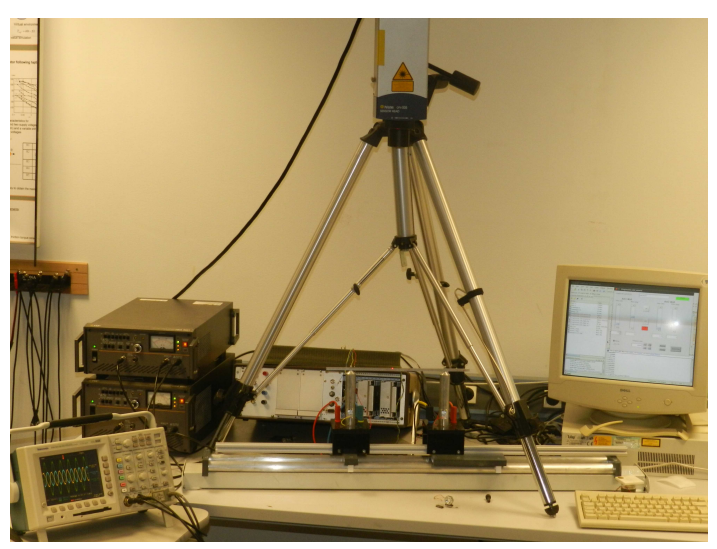

Fig. 7. The experimental setup

amplitude of the two actuators independently, through a DSP (TI 2812) and two amplifiers (HSA 4051).

\section{E. Identification of vibration modes}

A cartography was performed to measure the vibration amplitude of each point in the beam, for the mode shape A and $\mathrm{B}$ as shown in Fig.8. This is used to determine the deformation mode shapes $\phi_{x_{1}, x_{2}}$ we obtain:

$$
\left(\begin{array}{ll}
\phi_{A}\left(x_{1}\right) & \phi_{B}\left(x_{1}\right) \\
\phi_{A}\left(x_{2}\right) & \phi_{B}\left(x_{2}\right)
\end{array}\right)=\left(\begin{array}{cc}
-0.9680 & -0.6949 \\
1 & -0.7447
\end{array}\right)
$$

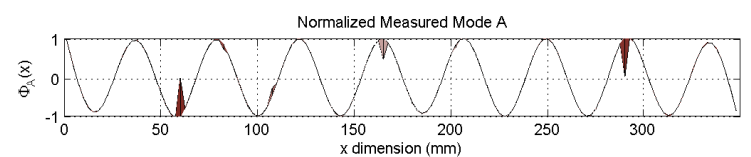

(a) Normalized measured mode $\mathrm{A}$ at $26373 \mathrm{~Hz}$

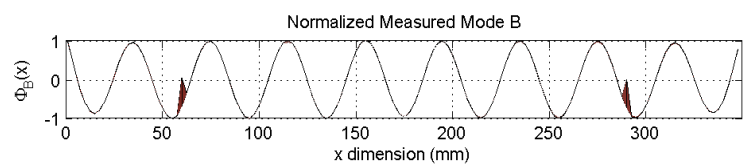

(b) Normalized measured mode B at $29369 \mathrm{~Hz}$

Fig. 8. Normalized measured mode A and B

\section{F. Control of excitation's vibration amplitude}

The modal amplitude and its relative phase can be controlled directly by controlling the vibration amplitude of transducers accordingly to eq.8. By substituting eq.12 in eq. 6 we obtain:

$$
\left(\begin{array}{l}
\underline{W}_{1} \\
\underline{W}_{2}
\end{array}\right)=\underline{W}_{B}\left(\begin{array}{ll}
\phi_{A}\left(x_{1}\right) & \phi_{B}\left(x_{1}\right) \\
\phi_{A}\left(x_{2}\right) & \phi_{B}\left(x_{2}\right)
\end{array}\right)\left(\begin{array}{l}
1 \\
j
\end{array}\right)
$$

In this paper $\psi_{B}$ is fixed to zero $\left(\underline{W}_{B}=W_{B}\right)$ giving rise to:

$$
\left(\begin{array}{l}
\underline{W}_{1} \\
\underline{W}_{2}
\end{array}\right)=W_{B}\left(\begin{array}{l}
\phi_{A}\left(x_{1}\right)+j \phi_{B}\left(x_{1}\right) \\
\phi_{A}\left(x_{2}\right)+j \phi_{B}\left(x_{2}\right)
\end{array}\right)
$$

This may be expressed as

$$
\left(\begin{array}{l}
\underline{W}_{1} \\
\underline{W}_{2}
\end{array}\right)=W_{B}\left(\left|\frac{\phi_{A, B}\left(x_{1}\right)}{\underline{\phi}_{A, B}\left(x_{2}\right)}\right| \begin{array}{l}
e^{j \alpha_{1}} \\
e^{j \alpha_{2}}
\end{array}\right)
$$

$\alpha_{1}$ and $\alpha_{2}$ are the phase shift between real and imaginary part of the deformation mode shape $\mathrm{A}$ and $\mathrm{B}$, at the position of transducers. Now a travelling wave can be obtained by imposing these phases on the right and the left transducer, or by imposing a phase shift $\alpha$ between the vibration amplitude of transducers with $\alpha=\alpha_{1}-\alpha_{2}$ accordingly to Fig.3(b). The vibration amplitude of travelling wave can be controlled directly by the vibration amplitude of transducers, then eq. 17 becomes:

$$
\left(\begin{array}{c}
\underline{W}_{1} \\
\underline{W}_{2}
\end{array}\right)=W_{A}\left(\begin{array}{c}
\left|\phi_{A, B}\left(x_{1}\right)\right| e^{j \alpha} \\
\left|\phi_{A, B}\left(x_{2}\right)\right|
\end{array}\right)
$$

A rotating reference frame related to the frequency of the vibration wave is introduced, using a Langevin transducer. The complex notation of the equation of motion about a vibration mode, and the decoupling according to two-axis allow a double independent closed loop control to regulate the real and imaginary parts of the vibration amplitude and its relative phase at any frequency, it acts directly on the amplitude of the supply voltage as a classical electromagnetic machines. 
The voltage $V_{q}$ is used to control the vibration amplitude $W_{d}$, while $V_{d}$ is used to control the vibration amplitude $W_{q}$, through a regulator $C(s)$ for each closed loop [8]. This control does not depend on frequency accordingly to Fig.9.

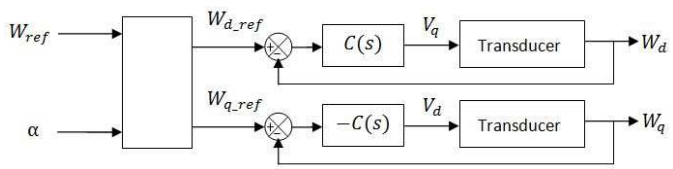

Fig. 9. schematic diagram control of a Langevin transducer

The vibration amplitude in rotating frame can be determined by

$$
\begin{gathered}
\underline{W}=W_{d}+j W_{q} \\
\underline{W}=W e^{j \alpha}
\end{gathered}
$$

where $W=\sqrt{W_{d}^{2}+W_{q}^{2}}$ and $\alpha=\arctan \frac{W_{q}}{W_{d}}$ are respectively the magnitude and the argument of $\underline{W}$. Then the vibration amplitude of the transducers in rotating frame are done by:

$$
\left(\begin{array}{l}
\underline{W}_{1} \\
\underline{W}_{2}
\end{array}\right)=\left(\begin{array}{l}
W_{d 1}+j W_{q 1} \\
W_{d 2}+j W_{q 2}
\end{array}\right)
$$

by substitution the identified modes eq.14 in eq.18 leads to

$$
\left(\begin{array}{l}
W_{d 1}+j W_{q 1} \\
W_{d 2}+j W_{q 2}
\end{array}\right)=W_{A}\left(\begin{array}{c}
1.24 e^{-j 108^{\circ}} \\
1.19
\end{array}\right)
$$

\section{RESULTS AND DISCUSSIONS}

\section{A. Travelling wave generation}

The generation of a travelling wave was possible by excitation with vibration amplitude. The frequency was in the range between the two resonance modes, $26373 \mathrm{~Hz}$ and $29369 \mathrm{~Hz}$. Accordingly to eq.22 a travelling wave can be obtained by imposing approximatively the same vibration amplitude in each transducer shifted with $108^{\circ}$.

In this paper a travelling wave was performed with a vibration amplitude of $0.5 \mu \mathrm{m}$, corresponding to vibration mode $W_{A}$ of $0.4 \mu \mathrm{m}$. Figure. 10 depicts the evolution of the vibration amplitude of each transducer in rotating frame eq.22. For a reference step amplitude $W_{1_{\text {ref }}}$ from 0 to $0.5 \mu \mathrm{m}$, with $\alpha_{1}=108^{\circ}$ for the first actuator (the red curve), ie a step reference $W_{d 1_{\text {ref }}}=0$ to $0.47 \mu \mathrm{m}$, and a step of $W_{q 1_{\text {ref }}}=0$ to $-0.15 \mu \mathrm{m}$. And for a reference step amplitude $W_{2_{\text {ref }}}$ from 0 to $0.5 \mu \mathrm{m}$ with $\alpha_{2}=0^{\circ}$ for the second actuator (the blue curve), ie a step reference $W_{d 2_{\text {ref }}}=0$ to $0.5 \mu \mathrm{m}$, and a step of $W_{q 2_{\text {ref }}}=0 \mu \mathrm{m}$.

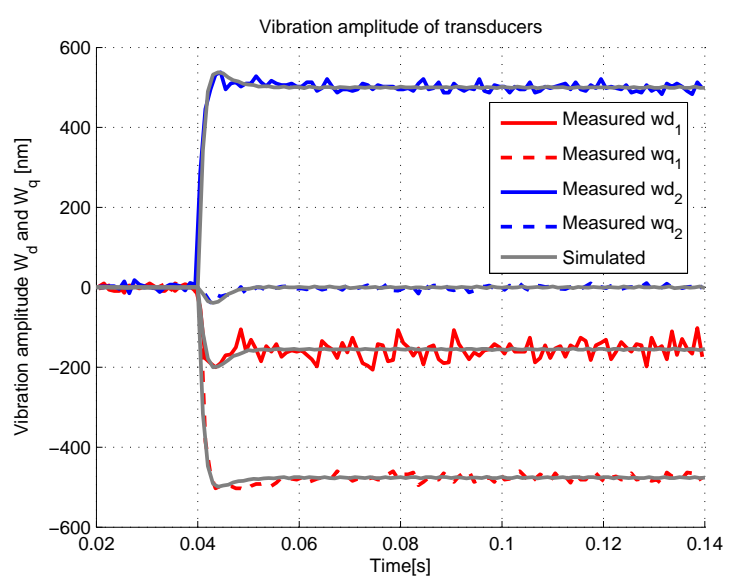

Fig. 10. Measured and simulated vibration amplitude of transducers

A pure travelling wave is obtained with standing wave ratio (SWR) nearly equal to 1 at each points of the beam as shown in Fig.11, even if we change the frequency between two neighboured neutral modes shapes [26373 29369] Hz. It should be noted that, when the beam is excited near the frequency of one vibration mode, the SWR is distancing from 1.

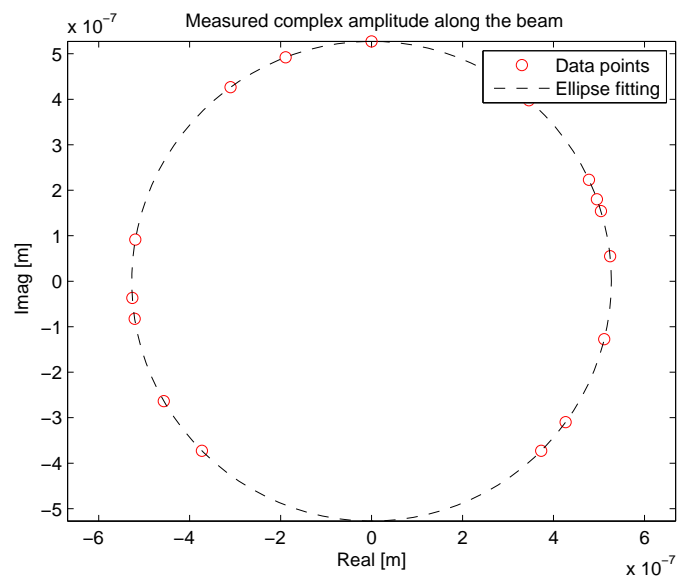

Fig. 11. Complex amplitude along the beam with $S W R \approx 1$

This complex amplitude is obtained by measuring the vibration amplitude and its phase shift with the voltage supply of the first actuator [5]. During the test, a normal force is applied on the beam surface, this force or this load is rejected as a perturbation, and the vibration amplitude of this travelling wave is kept constant along the beam.

\section{B. Direction change of the travelling wave}

The direction of travelling wave can be inverted by changing the phase difference of the first transducer from $108^{\circ}$ to $-108^{\circ}$. Figure 13 depicts the evolution of $W_{d}$ and $W_{q}$ as a function of time with a step phase shift from from $108^{\circ}$ to $-108^{\circ}$, with vibration amplitude of $0.5 \mu \mathrm{m}$, while the vibration amplitude of the second actuator is kept to $0.5 \mu \mathrm{m}$ with $\alpha=0^{\circ}$, ie a step reference $\underline{w}_{1_{\text {ref }}}=0.5 e^{j 108^{\circ}} \mu \mathrm{m}$ to $0.5 e^{-j 108^{\circ}} \mu \mathrm{m}$. 


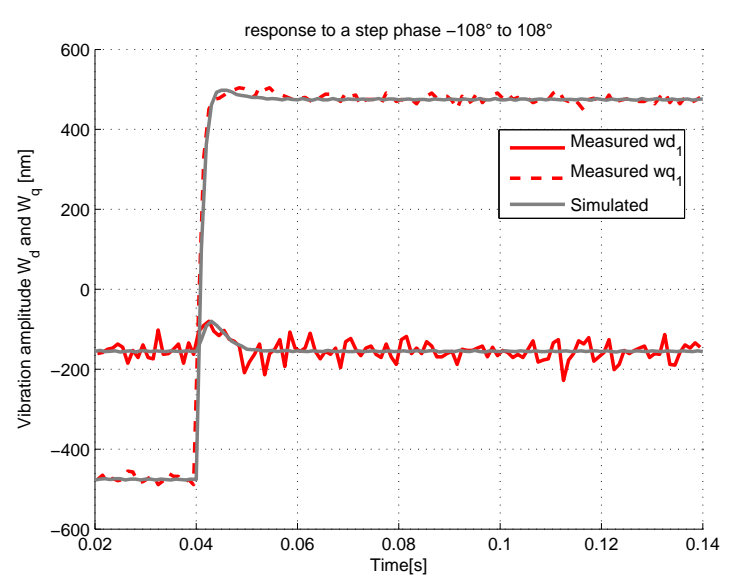

Fig. 12. Measured and simulated vibration amplitude of the left transducer for a step phase

A perfect travelling wave in the opposite direction is obtained in $10 \mathrm{~ms}$ accordingly the steady state.

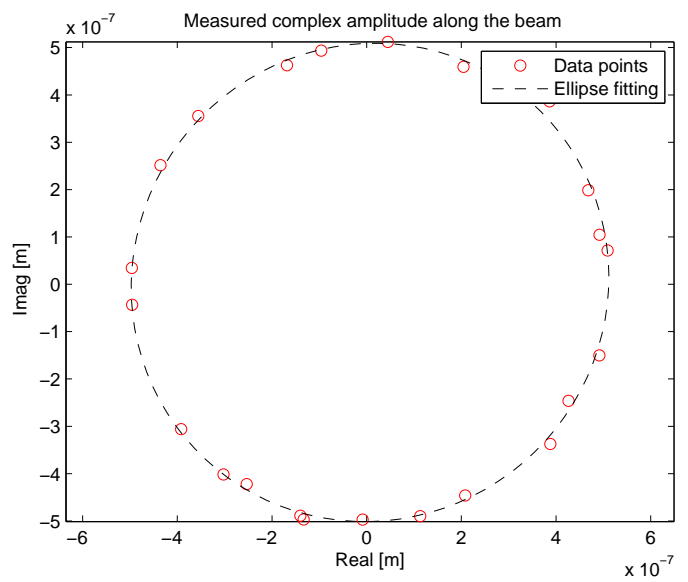

Fig. 13. Complex amplitude along the beam with in the opposite direction

\section{CONCLUSION}

In this paper, a new method is presented to generate a travelling wave, with excitation in vibration amplitude. A closed loop control is applied to each transducer to achieve this thanks to vector control method. A travelling wave has been produced and controlled in both direction and amplitude, with an optimum standing wave ratio.

\section{ACKNOWLEDGMENT}

This work has been carried out within the framework of the project StimTac of IRCICA (institut de recherche sur les composants logiciels et matériel pour la communication avancé), and the Project Mint of Inria.

\section{REFERENCES}

[1] T. Sashida and T. Kenjo, An Introduction to Ultrasonic Motors. Clarendon Press, 1993.
[2] M. Kurosawa and S. Ueha, High speed ultrasonic linear motor with high transmission efficiency, Ultrasonics, vol. 27, no. 1, pp. 3944, Jan. 1989.

[3] Y. Tomikawa, K. Adachi, H. Hirata, T. Suzuki, and T. Takano, "Excitation of a Progressive Wave in a Flexurally Vibrating Transmission Medium,” Jpn. J. Appl. Phys., vol. 29, no. S1, p. 179, Jan. 1990.

[4] B.-G. Loh and P. . Ro, "An object transport system using flexural ultrasonic progressive waves generated by two-mode excitation," IEEE Transactions on Ultrasonics, Ferroelectrics, and Frequency Control, vol. 47, no. 4, pp. 994-999, Jul. 2000.

[5] B. Dehez, C. Vloebergh, and F. Labrique, "Study and optimization of traveling wave generation in finite-length beams," Mathematics and Computers in Simulation, vol. 81, no. 2, pp. 290-301, Oct. 2010.

[6] A. Minikes, R. Gabay, I. Bucher, and M. Feldman, "On the sensing and tuning of progressive structural vibration waves," IEEE Transactions on Ultrasonics, Ferroelectrics, and Frequency Control, vol. 52, no. 9, pp. 1565-1576, Sep. 2005.

[7] C. Hernandez, Y. Bernard, A. Razek, "Theoretical and experimental analysis of a two mode excitation linear motor using piezoelectric actuators ," Actuator 2010, DE, 14 June 2010, Proceedings of Actuator 2010

[8] F. Giraud, C. Giraud-Audine, M. Amberg, and B. Lemaire-Semail, "Vector control method applied to a traveling wave in a finite beam," IEEE Transactions on Ultrasonics, Ferroelectrics, and Frequency Control, vol. 61, no. 1, pp. 147158, Jan. 2014.

[9] K. Nakamura and D. Koyama, "Non-contact transportation system of small objects using Ultrasonic Waveguides," IOP Conf. Ser.: Mater. Sci. Eng., vol. 42, no. 1, p. 012014, Dec. 2012.

[10] X. Li, Y. Sun, C. Chen, and C. Zhao, "Oscillation propagating in noncontact linear piezoelectric ultrasonic levitation transporting systemfrom solid state to fluid media," IEEE Transactions on Ultrasonics, Ferroelectrics, and Frequency Control, vol. 57, no. 4, pp. 951-956, Apr. 2010.

[11] Y. Hashimoto, Y. Koike, and S. Ueha, "Transporting objects without contact using flexural traveling waves," The Journal of the Acoustical Society of America, vol. 103, no. 6, pp. 3230-3233, Jun. 1998

[12] H. Hariri, Y. Bernard, and A. Razek, "Modeling and experimental study of a two modes excitation traveling wave piezoelectric miniuature robot," presented at the Actuator12, 2012, pp. 346-349.

[13] H. Hariri, Y. Bernard, and A. Razek, A traveling wave piezoelectric beam robot, Smart Mater. Struct., vol. 23, no. 2, p. 025013, Feb. 2014.

[14] G. H. Kim, J. W. Park, and S. H. Jeong, "Analysis of dynamic characteristics for vibration of flexural beam in ultrasonic transport system," J Mech Sci Technol, vol. 23, no. 5, pp. 1428-1434, May 2009.

[15] A. Kawamura and N. Takeda, "Linear ultrasonic piezoelectric actuator," IEEE Transactions on Industry Applications, vol. 27, no. 1, pp. 2326, Jan. 1991.

[16] Y. Ting, J. M. Yang, C. C. Li, C. C. Yang, and Y. C. Shao, "Modeling and Design of a Linear Actuator by Langevin Vibrators," in IEEE Ultrasonics Symposium, 2006, 2006, pp. 2337-2340.

[17] J. M. Fernandez and Y. Perriard, "Characteristics, modeling and simulation of a traveling wave ultrasonic linear motor," in 2004 IEEE Ultrasonics Symposium, 2004, vol. 3, pp. 2247-2250 Vol.3

[18] Y. Roh, S. Lee, and W. Han, "Design and fabrication of a new traveling wave-type ultrasonic linear motor," Sensors and Actuators A: Physical, vol. 94, no. 3, pp. 205-210, Nov. 2001.

[19] K. F. Graff, Wave Motion in Elastic Solids. Courier Corporation, 1975.

[20] M. Abu-Hilal, "Forced vibration of EulerBernoulli beams by means of dynamic Green functions," Journal of Sound and Vibration, vol. 267, no. 2, pp. 191-207, Oct. 2003.

[21] M. Kuribayashi, S. Ueha, and E. Mori, "Excitation conditions of flexural traveling waves for a reversible ultrasonic linear motor," The Journal of the Acoustical Society of America, vol. 77, no. 4, pp. 1431-1435, Apr. 1985.

[22] D.-A. Wang and H.-D. Nguyen, "A planar Bzier profiled horn for reducing penetration force in ultrasonic cutting," Ultrasonics, vol. 54, no. 1, pp. 375-384, Jan. 2014. 